\title{
Validation of Mini-Mental Adjustment to Cancer scale in a Moroccan sample of breast cancer women
}

Mohammed El Amine Ragala1,2, Jaouad El Hilaly ${ }^{3,4}$, Lamiae Amaadour ${ }^{5}$, Majid Omari ${ }^{1,6}$, Achraf E. L. Asril ${ }^{6}$, Mariam Atassi ${ }^{7,8}$, Zineb Benbrahim ${ }^{5}$, Nawfel Mellas ${ }^{5}$, Karima E. L. Rhazi ${ }^{6}$, Karima Halim ${ }^{1,9}$ and Btissame Zarrouq ${ }^{2,6^{*}}$ (D)

\begin{abstract}
Background: The Mini-Mental Adjustment to Cancer Scale (Mini-MAC) instrument is commonly used worldwide by professionals of oncology, but the scale has not, up to date, been validated in Arabic and Moroccan context, and there is an absence of data in the Moroccan population. This study aims to validate the Mini-MAC, translated and adapted to the Arabic language and Moroccan culture, in women with breast cancer.

Methods: Data were analyzed in two successive phases. First, exploratory factor analysis (EFA) was used to assess the factor structure in the pilot sample $(N=158)$. Then, this structure was confirmed in the validation sample $(N=$ 203) using confirmatory factor analysis (CFA).

Results: Confirmatory factor analysis confirmed Watson's original structure underlying the Mini-MAC items: Helpless/Hopeless, Anxious Preoccupation, Fighting Spirit, Cognitive Avoidance, and Fatalism. Absolute, incremental, and parsimonious fit indices showed a highly significant level of acceptance confirming a good performance of the measurement model. The instrument showed sufficient reliability and convergent validity demonstrated by acceptable values of composite reliability ( $C R=0.93-0.97$ ), and average variance extracted (AVE $=0.66-0.93$ ), respectively. The square roots of AVE were higher than factor-factor pairs correlations, and the Heterotrait-Monotrait ratio of correlations values were lesser than 0.85 , indicating acceptable discriminant validity.

Conclusions: reliability; and both convergent and discriminant validity tests indicated that the Arabic version of the Mini-MAC had a good performance and may serve as a valid tool measuring psychological responses to cancer diagnosis and treatment.
\end{abstract}

Keywords: Adjustment, Cancer, Mini-MAC, Oncology, Psychometric, Validity

\footnotetext{
* Correspondence: btissame.zarrouq@usmba.ac.ma

${ }^{2}$ Teachers Training College (Ecole Normale Superieure), Department of Biology and Geology, Sidi Mohamed Ben Abdellah University, P. B 5206 Bensouda, $30030 \mathrm{Fez}$, Morocco

${ }^{6}$ Laboratory of Epidemiology and Research in Health Sciences, Faculty of Medicine and Pharmacy, Sidi Mohamed Ben Abdellah University, 2.200 Route Sidi Harazem, 30070 Fez, KM, Morocco

Full list of author information is available at the end of the article
}

(c) The Author(s). 2021 Open Access This article is licensed under a Creative Commons Attribution 4.0 International License, which permits use, sharing, adaptation, distribution and reproduction in any medium or format, as long as you give appropriate credit to the original author(s) and the source, provide a link to the Creative Commons licence, and indicate if changes were made. The images or other third party material in this article are included in the article's Creative Commons licence, unless indicated otherwise in a credit line to the material. If material is not included in the article's Creative Commons licence and your intended use is not permitted by statutory regulation or exceeds the permitted use, you will need to obtain permission directly from the copyright holder. To view a copy of this licence, visit http://creativecommons.org/licenses/by/4.0/ The Creative Commons Public Domain Dedication waiver (http://creativecommons.org/publicdomain/zero/1.0/) applies to the data made available in this article, unless otherwise stated in a credit line to the data. 


\section{Background}

Nowadays, Non-communicable diseases (NCDs) represent the major health challenges for developing countries where the annual mortality rate exceeds largely that of all other diseases combined. Nearly $80 \%$ of NCDs deaths occur in low and middle-income countries [1]. As one of the African middle-income countries, Morocco is experiencing a substantial increase in the burden of NCDs along with a higher mortality rate, which represents around $75 \%$ of the total death in the country [2].

Breast cancer is one of the most common cancers in women around the world [3], the most prevalent deadly disease of women in low and middle-income countries, and is pictured as a symbol of the end of life [4]. It primarily concerns young women by targeting the breast, which is deemed as the most valuable thing in their life. The breast mirrors feminine valuableness, esthetic appearance, and motherhood [5].

Breast cancer is a leading cancer with an incidence of 10,136 new cases diagnosed in 2018, representing $19.2 \%$ of the overall cancer incidence and $36.9 \%$ of cancers diagnosed in Moroccan women. In terms of mortality, it is the second most common cancer for women, after lung cancer, with approximately 3518 deaths (12.3\% of total cancer deaths) [6]. As the magnitude of the breast cancer epidemic continues to expand, healthcare interventions become cost-effective for the health system. Aiming to maintain and deliver an effective and affordable service for sick people, the Moroccan health system is embracing a package of measures in parallel with an emerging paradigm called the biopsychosocial model [7]. The latter seeks to integrate the psychological and the social dimensions in the traditional biomedical model. Psychological aspects are described in terms of cognitions, emotions, and behaviors, whereas social aspects consist of social norms of behavior, pressures to change behavior, social values on health, social status, and ethnicity [8]. Understanding these elements helps to determine the styles of psychological adjustments in cancer patients. Oncology specialists believe that coping style is very relevant in making decisions about adjuvant therapy or active follow-up, coping with side effects of treatment, and anxiety caused by uncertainty in the prognosis [9].

Coping and mental adaptation are the most widely studied concepts in psychosocial oncology [10]. Coping requires constantly changing cognitive and behavioral efforts to manage specific external or internal demands that are appraised as taxing or exceeding the resources of a person [11]. Greer et al. (1989) defined mental adjustment as cognitive and behavioral responses made by an individual to the diagnosis of cancer [12]. There are many scales to assess coping strategies such as "The Ways of Coping Checklist” (WCC) [13], “The Coping
Inventory For Stressful Situations" (CISS), [14], and "The Coping with Health Injuries and Problems Scale" (CHIPS) [15]. On the other hand, some scales were developed to measure psychological adjustment like "The adjustment inventory" (adult form), which provides five measures of personal and social adjustment [16], "The ATT39 scale" used as a norm-referenced measure of emotional adjustment in diabetic patients [17], and "The Mental Adjustment to Cancer (MAC) Scale [12, 18].

The "Mental Adjustment to Cancer" (MAC) is a 40item scale distributed over five subscales and has become a widely used instrument for assessing psychological adjustment in cancer patients. Several studies have tried to validate the MAC subscales, but they were not able to replicate the original factor structure [19, 20]. Hence, the original version was revised by Watson [21], leading to a 29-item scale with psychometric properties comparable to the original MAC scale. The shortened version was called the "Mini-Mental Adjustment to Cancer Scale" (Mini-MAC). It consists of five scales ((Helpless/Hopeless $(\mathrm{HH})$, Anxious Preoccupation (AP), Fighting Spirit (FS), Cognitive Avoidance (CA), and Fatalism (FA).

The Mini-MAC, distilled from the MAC, has been translated into several other languages and investigated by many studies. Some authors have confirmed the original five-factor structure of the original Mini-MAC [22-25], while others proposed different structures of two [26], three [27], four [28-30], or five factors [22, 24, 25, 27, 31].

Among the five original factors, the fatalism subscale has sparked much debate among authors. Originally defined as a maladjustment style, fatalism was supposed to be adopted by patients to accept the situation as inevitable. Meanwhile, other studies [27] have considered it as an adaptive measure to religion, faith, reassessment, positive thinking, and acceptance [25, 30, 32]. Fatalism was found to be positively correlated with spirituality and active participation in religious practice but was not associated with a perceived lack of control and acceptance of results. The fatalism of Mini-MAC may be more associated with feelings of personal control and that it has a positive effect on the health of women with breast cancer [27].

Literature review reports incongruity and dissonance between authors' findings regarding the Mini-MAC's factor structure. This is due to many variables such as methodological issues, types and stages of cancer, and sample sizes. Together, these minor and major discrepancies of unstandardized studies would have impeded obtaining unified and robust factor solutions [33]. In addition, most validation studies of the Mini-MAC scale are not well-grounded and should be taken with caution. Indeed, though EFA is discouraged to draw substantive 
conclusions from a scale structure [34], few studies have conducted CFA to investigate the validation of the MiniMAC scale [24, 28, 35].

Cancer is one of the most stressful diseases. Coping with cancer is a long-term process in which patients use different strategies to cope with the physical, psychological, and social controversies caused by the disease. The choice of coping strategies depends both on individual variability and temporal variability. The former arises from the patient's personality traits, disease type, treatment, perceived support, etc. while the latter is associated with the stage of the disease and its course [36]. Though some strategies are in general better than others, most often they are associated with an optimal degree of psychological adjustment [37]. The provision of adequate mental support, which would enable patients to adopt constructive strategies to cope with the stress associated with the disease at each stage, is of great importance in the process of treatment and rehabilitation of patients with the cancer disease [36]. Since the psychological state of the patient can predict the progression and course of the disease [38], knowledge regarding adaptation to neoplastic disease should facilitate a detailed diagnosis and allow assessment of the mental, emotional and social status of a patient throughout the follow-up. Subsequently, appropriate intervention measures can be taken and the quality of life of cancer patients can be improved [36]. The MAC scale in its original version was used as a measure of psychological adjustment in cancer-diagnosed patients. Then, by the same token, the scale served various purposes: (a) to measure the clinical progress of patients and improve the clinical support provided to them; (b) to assess the effectiveness of psychotherapy; (c) to determine the effectiveness of various strategies and their evolution over time, and (d) to assess the possible impact of the adjustment on quality of life and survival [39]. As the Mini-MAC is strongly linked to the original scale (MAC) [21], we presume that the Arabic version of Mini-MAC would be of paramount usefulness for clinicians. It may help them to explore the four dimensions cited above, to permit the clinical understanding of the adaptation process affecting the quality of life and physical outcomes, and to link it prospectively to specific psychosocial services for early intervention in patients' psychiatric morbidity.

The Mini-MAC instrument is commonly used worldwide by professionals of oncology, but the scale has not, up to date, been validated in Arabic and Moroccan context, and still, there is a lack of data on the Moroccan population. To this end, the present study aims to examine the factor structure, reliability, and validity of the Mini-MAC among breast cancer women in Morocco. In this line, the five first-order latent factors of the Mini-
MAC original version were examined using Confirmatory factor analysis (CFA).

\section{Methods \\ Mini-MAC utility}

Some investigations have evaluated the feasibility of the Mini-MAC in research and clinical settings [40]. For research, the Mini-Mac is considered one of many tools used to evaluate the prognosis of patients with psychological disorders in longitudinal studies. To understand how psychological coping variables change as the duration of the cancer disease increases, the assessment is realized from diagnosis to follow-up [40]. In clinical care, the Mini-MAC can be used to measure adaptive and maladaptive coping of cancer patients that may be subjected to positive-coping programs [28]. Overall, the Arabic version of Mini-MAC may be useful both in psycho-oncology research and clinical practice. It can also assess the response to cancer diagnosis and treatments and categorize patients who may endure later psychological adjustment difficulties.

\section{Mini-MAC scale translation}

The original version of the Mini-MAC scale was translated from English to Arabic, then reviewed by an expert group, and finally translated back into English by two independent translators who are unfamiliar with the MiniMAC scale. Back translation was checked by English experts and corrected based on comments. After it was estimated as satisfying, the committee decided on the final Arabic version. The latter was then pilot tested asking 20 breast cancer women to complete and comment on the questionnaire. No item was noticed to be difficult to understand or confusing. Hence, no revision was made after the pilot test.

\section{Participants and procedure}

A consecutive series of breast cancer women attending routine follow-up appointments at a public oncology hospital in Fez city were recruited. All the recruited women were under active treatment. They were included based on inclusion criteria: diagnosed with histologically confirmed breast cancer, aged 18 years or above. Of the total, $243(67.3 \%)$ of the women were illiterate but understand spoken Arabic, and only 118 (32.7\%) were able to read and write the language. The participants were able to consent, communicate, and carry out the interview. They were not confined to their chairs or beds and were aware of their cancer diagnosis. To measure the coping styles of patients with cancer, the recruited women were interviewed to fill the Mini-MAC questionnaire, and their demographic and clinical characteristics were collected. All the participants were notified about the aim of the study; their written approval to answer 
the questionnaires was given and approved by the hospital-university ethics committee of Sidi Mohamed Ben Abdellah University (N 24/18).

\section{Measures}

Mini-Mental Adjustment to Cancer Scale (Mini-MAC) consists of 29 items on a four-point Likert scale ranging from "Definitely does not apply to me" to "Definitely apply to me". It assesses five cognitive subscales: helpless/hopeless (HH, 8 items), anxious preoccupation (AP, 8 items), fighting spirit (FS, 4 items), cognitive avoidance (CA, 4 items), and fatalism (FA, 5 items). In phase 1, the 29-item Mini-MAC (original version) was piloted with 158 breast cancer women between February 2018 and April 2018. In phase 2, the modified 24-item Mini-MAC instrument (version 2) was distributed to 203 breast cancer women between Mai 2018 and July 2018.

\section{Statistical analyses}

Statistical data analyses were performed on the $\mathrm{R}$ program with packages "psych", "semTools", and "lavaan". Mini -MAC items on the whole sample were first analyzed by descriptive statistics. Then, the structure and internal consistency of the Mini-MAC questionnaire were tested. The suitability of the correlation matrix was verified, to ensure that it is factorized based on the Kaiser-Meyer-Olkin (KMO) test and Bartlett's sphericity test [41]. The factorial structure of the Mini-MAC instrument was examined on the first sample $(N=158)$ using Exploratory Factor Analysis (EFA). The violation of the assumption of multivariate normality was assessed by Mardia's test [42]. To determine the appropriate number of factors to extract, and due to the skewed ordinal, parallel analysis of polychoric correlations with PCA as a method of extraction was performed [43]. Whereas, the EFA was done by principal axis factoring (PAF), an extraction method, and oblimin rotation. To get the most parsimonious factor structure, the items with low communalities (less than 0.20), the significant cross-loaded items, and the unrepresentative ones were eliminated from the analysis. This was performed in a stepwise fashion; the EFA was rerun after each step [44]. The reliability of the Mini-MAC Scale was assessed based on its internal consistency, by determining Cronbach's alpha coefficient. The theoretical model of the Mini-MAC instrument was tested by confirmatory factor analysis (CFA). A 24-item confirmatory factor analysis was conducted on the whole sample $(N=203)$ using item-level ordered categorical data because items' level of measurement is ordinal. Hence, CFA was performed using a polychoric correlation matrix and diagonal weighted least squares (DWLS) robust estimation technique. The internal consistency was estimated by computing composite reliability (CR), convergent validity was assessed using the average variance extracted (AVE), and discriminant validity was tested by the FornellLarcker criterion and Hetereotrait-Monotrait (HTMT) ratio [45]. The Fitness of the measurement model was reported from three categories of incremental fit (CFI, IFI, AGFI); 2) absolute fit (RMSEA, GFI), and 3) parsimonious fit (Chisq/df).

\section{Results \\ Sample characteristics}

The study population consisted of two samples of patients with breast cancer. The first sample $(\mathrm{N}=158)$ was analyzed by exploratory factor analysis, while the second one $(N=203)$ was tested by confirmatory factor analysis. The two samples presented similar demographic characteristics (Table 1). The mean age was $49.01 \pm 11.38$ (range 27-83) and 48.86 \pm 11.65 (range 26-88) for the first and second samples, respectively. $68.35 \%$ of the patients in the first sample were married against $67.98 \%$ in the second. In terms of the level of education, most patients of the two samples were illiterate $(67.09 \%$ versus $67.49 \%)$. Most of the patients lived in an urban environment, and stage II cancer dominated in the two samples (50.63\% versus $50.25 \%)$.

\section{Exploratory factor analysis}

The underlying factor structure of the Mini-MAC was examined by analyzing the data from the first convenience sample drawn from that part of the population that was easy to reach, which satisfied the inclusion criteria $(n=158)$. The sampling adequacy for performing the analysis was verified through the Kaiser-Meyer-Olkin test (KMO). The total KMO value was 0.89 , and all KMO values for individual items were higher than 0.67, well above the acceptable limit of 0.60 [46]. Bartlett's test of sphericity $(\mathrm{x} 2=3188.57, \mathrm{df}=406, p<.001)$ indicated that inter-item correlations were sufficiently large to perform EFA.

Parallel analysis of polychoric correlation with PCA as a method of extraction and Velicer MAP criterium supported the adequacy of a five-factor solution. Factorial analysis with Principal axis factoring (PAF) as extraction method and oblimin rotation has yielded the first structure resembling nearly the authentic Mini-MAC version (Table 2). A loading cutoff point of at least 0.30 was initially used. Items that failed to load higher than this threshold or loaded significantly onto multiple factors were rejected from all factors. After each run, the analysis of the rotated factor matrix showed the significant factor loadings and the changes in communalities values. If an observed variable was not significant, it was eliminated from the measurement model. In each case that a variable was dropped, the model was respecified and run again. This was done over multiple iterations until a structured 
Table 1 Socio-demographic and clinical characteristics of the participants

\begin{tabular}{|c|c|c|c|c|}
\hline & \multicolumn{2}{|c|}{ Phase $1(N=158)$} & \multicolumn{2}{|c|}{ Phase $2(N=203)$} \\
\hline & Mean & N (\%) & Mean & N (\%) \\
\hline $\mathrm{Age}^{\mathrm{a}}$ & $\begin{array}{c}49.01 \pm 11.38 \\
\text { (Range 27-83) }\end{array}$ & & $\begin{array}{c}48.86 \pm 11.65 \\
\text { (Range 26-88) }\end{array}$ & \\
\hline \multicolumn{5}{|l|}{ Marital status } \\
\hline Unmarried & & $21(13.29)$ & & $28(13.79)$ \\
\hline Married & & $108(68.35)$ & & $138(67.98)$ \\
\hline Widowed & & $20(12.66)$ & & $26(12.81)$ \\
\hline Divorced & & $9(5.70)$ & & $11(5.42)$ \\
\hline \multicolumn{5}{|l|}{ Employment } \\
\hline Employed & & $14(8.86)$ & & 19 (9.36) \\
\hline Unemployed & & $25(15.82)$ & & $35(17.24)$ \\
\hline Housewife & & $96(60.76)$ & & $121(59.61)$ \\
\hline Retiree & & $23(14.56)$ & & $28(13.79)$ \\
\hline \multicolumn{5}{|l|}{ Education } \\
\hline Illiterate & & $106(67.09)$ & & $137(67.49)$ \\
\hline Primary education & & $29(18.35)$ & & $39(19.21)$ \\
\hline Secondary education & & $17(10.76)$ & & 19 (9.36) \\
\hline Higher Education & & $6(3.80)$ & & $8(3.94)$ \\
\hline \multicolumn{5}{|l|}{ Living environment } \\
\hline Urban & & $90(56.96)$ & & 119 (58.62) \\
\hline Rural & & $68(43.04)$ & & $84(41.38)$ \\
\hline \multicolumn{5}{|l|}{ Cancer stage ${ }^{b}$} \\
\hline$\|$ & & $80(50.63)$ & & $102(50.25)$ \\
\hline III & & $30(18.99)$ & & $38(18.72)$ \\
\hline IV & & $48(30.38)$ & & $59(29.06)$ \\
\hline
\end{tabular}

${ }^{a}$ (Mean \pm SD), ${ }^{b}$ Four missing values for $N=203$.

rotated factor matrix was found and communalities of all remaining observed variables were greater than 0.20 .

Accordingly, Items 3, 9, 22, and 27 cross-loaded significantly onto two different factors and were thus dropped from this model. Item 25 was removed because it failed to load significantly onto any factor. Despite the loss of five items in the factorial composition, the refined model replicated the five factors structure of the original version of Mini-MAC subscales (Helpless/Hopeless, Anxious Preoccupation, Fighting Spirit, Cognitive Avoidance, and Fatalism). The current five factors were constituted of the items making up the original scales. Hence, the factor names were maintained, and the fivefactor model (model 1: HH, AP, FS, CA FA) was then assessed by CFA. The five factors, with eigenvalues between 1.62 and 4.26, and composed of 3 to 7 items, explained a total variance of $63 \%$ (Table 2).

\section{Internal consistency}

The reliability of the Mini-MAC scale was assessed based on its internal consistency by determining
Cronbach's alpha coefficient. Cronbach's alpha and item-total correlations (corrected) were calculated for each construct and statement item, respectively (Table 2). The Fatalism construct showed a minimum alpha value of 0.71 , the remaining subscales exhibited alpha values between 0.88 and 0.94 , which confirmed a very good internal consistency. The alpha values need to be at least 0.70 and ideally above 0.80 to be considered as a good consistency. This means that all constructs were reliable.

The minimum item-total correlation calculated was 0.50 . The threshold for item-total correlations should be greater than 0.30 [41]. Table 2 illustrates that all of the constructs and statement items were unidimensional and had sufficient and acceptable internal consistency.

\section{Confirmatory factor analysis Interscale correlations}

The highest and most significant correlations $(p<0.001)$ were observed within two groups of factors, termed maladjustment ( $\mathrm{HH}$ and $\mathrm{AP}$ ) and positive adjustment (FS, 
Table 2 Factor structure of the Moroccan version of Mini-MAC (24 items)

\begin{tabular}{|c|c|c|c|c|c|c|c|c|}
\hline \multirow[t]{2}{*}{ Items $^{a}$} & \multicolumn{5}{|c|}{ Factors $^{b}$} & \multirow[t]{2}{*}{ h2 } & \multirow{2}{*}{$\begin{array}{l}\text { Item-total } \\
\text { correlation }\end{array}$} & \multirow[t]{2}{*}{ Alpha } \\
\hline & $\mathrm{HH}$ & AP & $C A$ & FS & FA & & & \\
\hline $\mathrm{HH} 5$ & .86 & -.13 & -.12 & .00 & .05 & .64 & .74 & .91 \\
\hline $\mathrm{HH} 4$ & .76 & .10 & .02 & -.02 & .09 & .65 & .73 & \\
\hline $\mathrm{HH} 7$ & .71 & .08 & -.01 & -.11 & -.05 & .69 & .78 & \\
\hline $\mathrm{HH} 6$ & .69 & .06 & .12 & .16 & -.16 & .56 & .76 & \\
\hline $\mathrm{HH} 2$ & .62 & .16 & .05 & -.01 & .00 & .54 & .70 & \\
\hline $\mathrm{HH} 8$ & .60 & .11 & .02 & -.15 & -.12 & .62 & .83 & \\
\hline $\mathrm{HH} 1$ & .60 & .17 & -.05 & -.08 & .02 & .56 & .76 & \\
\hline AP12 & -.01 & .81 & -.01 & .03 & .02 & .63 & .78 & .88 \\
\hline AP14 & .03 & .80 & .03 & .02 & -.11 & .71 & .84 & \\
\hline AP11 & .00 & .78 & -.08 & -.02 & .10 & .59 & .75 & \\
\hline AP16 & .06 & .73 & .04 & .01 & -.04 & .60 & .78 & \\
\hline AP13 & .05 & .65 & .05 & -.03 & -.01 & .47 & .68 & \\
\hline AP10 & .22 & .49 & -.01 & -.04 & .09 & .41 & .63 & \\
\hline AP15 & .25 & .37 & .02 & .03 & -.22 & .42 & .57 & \\
\hline CA24 & .06 & -.09 & .95 & -.02 & -.04 & .91 & .91 & .88 \\
\hline CA23 & -.02 & .06 & .89 & .04 & .06 & .91 & .84 & \\
\hline CA21 & -.08 & .05 & .88 & .00 & .03 & .89 & .87 & \\
\hline FS17 & -.04 & .02 & -.02 & .91 & .02 & .85 & .91 & .94 \\
\hline FS18 & .00 & .07 & -.05 & .90 & -.01 & .76 & .84 & \\
\hline FS19 & .03 & -.09 & .15 & .78 & .04 & .77 & .87 & \\
\hline FS20 & -.26 & -.17 & .10 & .34 & .17 & .51 & .57 & \\
\hline FA26 & .01 & .05 & .03 & -.06 & .80 & .60 & .70 & .71 \\
\hline FA29 & .01 & -.11 & .05 & .19 & .70 & .25 & .80 & \\
\hline FA28 & -.28 & .15 & .07 & .04 & .34 & .70 & .50 & \\
\hline Eigenvalue & 4.26 & 3.82 & 2.66 & 2.72 & 1.62 & & & \\
\hline Variance (total = 63\%) & $18 \%$ & $16 \%$ & $11 \%$ & $11 \%$ & $7 \%$ & & & \\
\hline
\end{tabular}

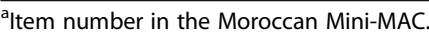

${ }^{\mathrm{b}}$ Abbreviations for the original Mini-MAC subscales: AP Anxious Preoccupation; HH Helpless-Hopeless; FS Fighting Spirit; FA Fatalism; CA Cognitive Avoidance.

CA, and FA) factors. Factors of the same group, either adjustment or maladjustment, correlated positively with each other. However, the correlations between the factors of the two groups correlated negatively $(r=-0.03$ to -0.70$)$. FS, CA, and FA correlated negatively with $\mathrm{HH}$ and AP $(r=-0.03$ to -0.65$)$ but correlated positively with each other $(r=0.43-0.77)$. AP showed a moderate negative correlation with Fatalism $(r=-0.42, p<0.001)$ and Fighting Spirit $(r=-0.40, p<0.001)$, and insignificant correlation with CA $(r=-0.03, p=$ ns). FS showed a high and positive correlation with Fatalism $(r=0.77, p<0.01)$, and a moderate and positive correlation $(r=0.43)$ with CA. On the other hand, CA and Fatalism have a positive significant correlation $(r=0.56)$ (Table 3).

\section{Convergent validity}

The first-order confirmatory factor analysis results also showed that the standardized regression coefficients exceeded 0.60; the smallest factors loadings (0.61) occurred at AP factor (item AP15). The remaining 23 factors were all greater than 0.70 . In addition, the t-ratio (the $t$-value is calculated by dividing the parameter estimate by the standard error) associated with each factorfactor pair and factor-variable pair exceeded 1.96, which indicated a significant relationship with a $p$-value less than 0.05 . The regression coefficients greater than 0.50 and the significant relationships associated with the high $\mathrm{t}$-scores indicated that the first-order confirmatory factor analysis had statistically gathered acceptable evidence for convergent validity [41] (Fig. 1).

As the result of the CFA (Fig. 1), the structure of the hypothesized model of the 24-item Mini-MAC instrument was confirmed. The reliability and convergent validity of the instrument were also asserted, with high values for the CR (0.93-0.97) and AVE (0.66-0.93), respectively. Therefore, the whole process of factor 
Table 3 Composite reliability, average variance extracted, maximum and average shared variance, and correlations between constructs

\begin{tabular}{|c|c|c|c|c|c|c|c|c|c|}
\hline \multirow[t]{2}{*}{ Latent Constructs } & \multirow[t]{2}{*}{ CR } & \multirow[t]{2}{*}{ AVE } & \multirow[t]{2}{*}{ MSV } & \multirow[t]{2}{*}{ ASV } & \multicolumn{5}{|c|}{ Latent Constructs } \\
\hline & & & & & 1 & 2 & 3 & 4 & 5 \\
\hline 1. Helpless-Hopeless & .95 & .75 & .62 & .41 & .86 & & & & \\
\hline 2. Anxious Preoccupation & .93 & .66 & .62 & .24 & $.79^{\mathrm{a}}$ & .81 & & & \\
\hline 3. Fighting Spirit & .97 & .89 & .59 & .41 & $-.70^{\mathrm{a}}$ & $-.40^{b}$ & .94 & & \\
\hline 4. Cognitive Avoidance & .97 & .93 & .41 & .20 & $-.30^{b}$ & -.03 & $.43^{b}$ & .96 & \\
\hline 5. Fatalism & .93 & .82 & .59 & .38 & $-.65^{\mathrm{a}}$ & $-.42^{b}$ & $.77^{\mathrm{a}}$ & $.56^{\mathrm{b}}$ & .90 \\
\hline
\end{tabular}

b $p<0.01 ;$ a $p<0.001$.

$C R$ Composite reliability; AVE the square root of the average variance extracted; MSV Maximum Shared Variance; ASV Average Shared Variance.

analysis was confirmed, and the Mini-MAC instrument fitted the data fairly well (Table 3).

\section{Discriminant validity, Fornell and Larcker criterion}

In Table 3, the bolded values are the square root of Average Variance Extracted (AVE) of each dimension, whereas other values are inter-correlation among the latent factor dimension. The highest correlation value between factors was 0.79 (between $\mathrm{HH}$ and AP), while the smallest value among the square root of AVE values was 0.81 . The findings warranted the discriminant validity of all model factors since the matrix diagonal values were higher than the off-diagonal values in the corresponding rows and columns. Average Shared Squared Variance (ASV) and Maximum Shared Squared Variance (MSV) were less than Average Variance extracted (AVE). HTMT value that is lesser than .85 or .90 [47], indicates a good discriminant validity. It appears from Table 4 that all matrix values are below 0.85 , which pleads in favor of possible discriminant validity between all constructs of the proposed model. Overall, reliability and both convergent and discriminant validity tests indicated that the proposed constructs of the measurement model were justified at least with these two types of tests (Fornell and Larcker Criterion, and HTMT).

\section{Fitness of the measurement model}

Evaluating the first-order measurement model included calculating the goodness-of-fit statistics and the standardized regression coefficients from the standardized model. The fit statistics for the first-order measurement model were $\chi^{2}=225(p=0.77)$, root mean square error of approximation (RMSEA) $=0.040$, Goodness of Fit Index $(\mathrm{GFI})=0.99$, adjusted goodness of-fit index $(\mathrm{AGFI})=0.98$, and comparative fit index $(\mathrm{CFI})=0.98$, normed fit index $(\mathrm{NFI})=0.98$, and Chi - square/ degrees of freedom $\left(\chi^{2} / \mathrm{df}\right)=0.93$ (Table 5$)$.

The fitness of the first-order model was assessed by three categories of fit statistics: absolute fit, parsimony correction, and incremental indices. These goodness-offit measures were highly acceptable when following the threshold values for fit statistics: the $\mathrm{X} 2 / \mathrm{df}$ should be less than 3, CFI should be greater than 0.95, NFI should be greater than 0.90, AGFI should be greater than 0.90, and the RMSEA should be less than 0.05 [41, 48]. Based on these ranges, all values were within acceptable threshold values. Therefore, the measurement model showed a good fit for the observed variables and relational contracting norm latent factors.

\section{Discussion}

The major purpose of this work was to develop an Arabic version of the Mini-MAC instrument useful in the Moroccan context. To this end, two samples of 158 and 203 breast cancer women were investigated. The majority of women in the present sample were illiterate (67.5\%) and housewives (65.9\%). These quite specific sociodemographic characteristics are understandable in the light of the Moroccan reality where $52.6 \%$ of women aged 15 years old and above are illiterate, and only $24.7 \%$ are active [49]. The demographics of our sample are similar to those of several studies carried out in Morocco on patients with breast cancer [50-53], but certainly different from the characteristics of the samples used to validate the Mini-Mac in countries that differ from Morocco on a socio-cultural and economic level [27, 54].

Using exploratory and confirmatory factor analysis, and after dispatching five items, the current version was validated yielding the five-factors structure of the original version of the Mini-MAC instrument (Helpless/ Hopeless, Anxious Preoccupation, Fighting Spirit, Avoidance, and Fatalism). The same structure, proposed originally by Watson et al., has been already validated by many authors working on different types of cancer [21$25,27]$. Our validated version showed similar psychometric properties as the original version [21], and other Mini-MAC validated versions [23, 25, 28-30].

The only difference between previous findings and ours resides in the degree of factors reliability and the factor intercorrelations. In this study, the coefficients reliability for AP, FS, CA, and FA are significantly high 


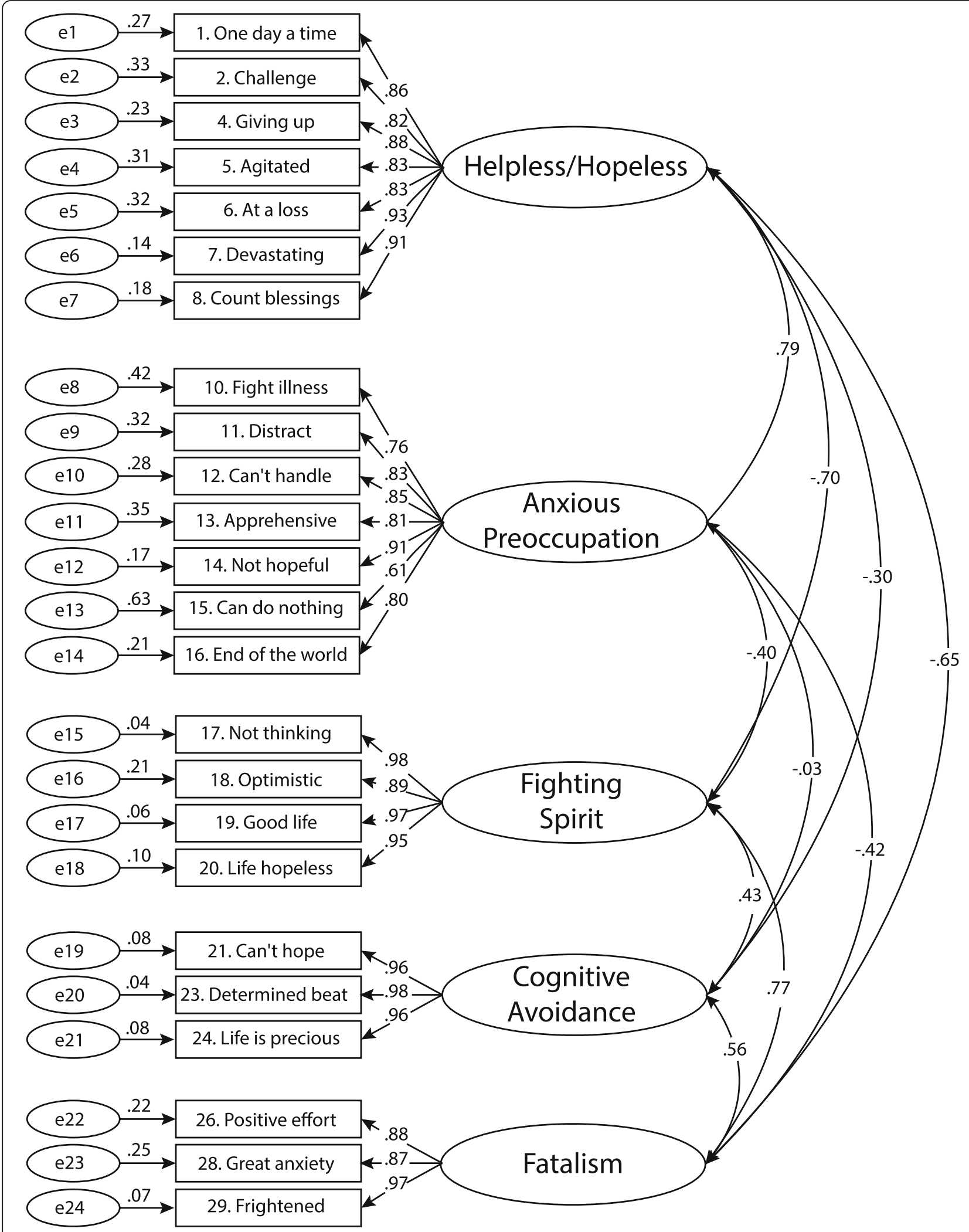

Fig. 1 CFA measurement model 
Table 4 Discriminant validity analyses: Heterotrait-Monotrait (HTMT) Criterion results

\begin{tabular}{|c|c|c|c|c|c|}
\hline & Helpless-Hopeless & Anxious Preoccupation & Fighting Spirit & Cognitive Avoidance & Fatalism \\
\hline Helpless-Hopeless & 1 & & & & \\
\hline Anxious Preoccupation & .76 & 1 & & & \\
\hline Fighting Spirit & .52 & .30 & 1 & & \\
\hline Cognitive Avoidance & .19 & .06 & .48 & 1 & \\
\hline Fatalism & .49 & .29 & .61 & .35 & 1 \\
\hline
\end{tabular}

compared to some previous studies [21, 23, 24, 30], but seem nearly similar to others $[25,31]$.

The factors belonging to the group of passive coping strategies or maladjustment (HH/AP) are positively correlated with each other, but negatively correlated to those belonging to the group of active coping strategies or adjustment (FS, CA, and FA), and vice versa. This contradicted the original study [21] and corroborated that of Patoo [25], which demonstrated the same trend of correlation between these factors. CA showed a significant positive correlation with FS as well as with FA. Only the second association was pointed out in the original study [21], while the same results were reported by other studies [23, 24, 27, 30]. In line with Watson et al's work [21], our findings also showed mild negative correlations between $\mathrm{CA}$ and $\mathrm{AP}$, and a high negative correlation between $\mathrm{CA}$ and $\mathrm{HH}$. The latter correlation was reported only by Patoo [25] who showed a mild negative correlation between the two factors. Indeed, these results, and in contrast to most previous studies, suggest that $\mathrm{CA}$ is an indicator of positive adjustment, and is positively associated with FS and FA. Nevertheless, many authors consider $\mathrm{CA}$ as an active distraction strategy that may facilitate problem-focused coping [25, 27, 32].

Some studies have grouped Mini-MAC factor adjustment to cancer into two types of strategies: passive coping strategies (Fatalism, Anxious Preoccupation, and Helpless/Hopeless), and active strategies (Fighting Spirit and Cognitive Avoidance) [22, 55]. However, this is not the case for the current study, where fatalism and Cognitive Avoidance were found as positive coping styles [25, 27], and not maladjustment as is stated by some authors [24, 28]. Besides, a Chinese study has divided Mini-MAC subscales into two groups called Negative and Positive Emotions. The first one, an indicator of maladjustment, includes Anxious Preoccupation and Hopelessness, whereas the second, indicator of positive adjustment, includes Fatalism and Fighting Spirit. The positive emotion group was found significantly associated with Cognitive Avoidance [27].

Fatalism showed a negative correlation with the factors of the passive coping strategies and a positive correlation with those of the active strategies. These findings corroborated some studies [24, 25, 30,32], and at the same time contradicted others [22, 23, 28].

In contrast to western countries, Fatalism is considered as a positive coping strategy in Moroccan culture, the same results have been found in Persian, Korean, and Chinese countries [25, 27, 30]. Of particular note, Moslem people found their faith in destiny and fatalism, which has a different connotation from western countries; fatalism means acceptance and satisfaction based on the person's reasons first, and then trust in God. This means that a positive attitude gathers fatalism with a fighting spirit. These findings are consistent with those of Islamic [25] and Asiatic versions [27, 30, 32] while they contrast with those of most western countries [2224, 28]. They have asserted that Fatalism represents a positive adaptation and psychological battle with cancer. Our findings confirm the previous argument that FA is an adaptive coping tendency that does not correlate with distress [30, 31].

These interpretations should consider some caveats concerning methodological issues. In this light, most previous studies of Mini-MAC validation are based on exploratory factor analysis, which makes them less reliable [21, 23, 25, 27-31]. Whereas few studies are grounded on confirmatory factor analysis [22, 23, 32]. Additionally, the factor structure reported by different unstandardized studies should be variant due to many variables such as the type of cancer, sample size, culture, age, gender, patients, and phases of cancer. To deduce

Table 5 Overall fit indices of the CFA model

\begin{tabular}{|c|c|c|c|c|c|c|c|}
\hline \multirow[b]{2}{*}{ Fit index } & \multicolumn{3}{|c|}{ Absolute Fit } & \multicolumn{3}{|c|}{ Incremental Fit } & \multirow{2}{*}{$\begin{array}{l}\text { Parsimonious Fit } \\
\mathrm{X}^{2} / \mathrm{df}\end{array}$} \\
\hline & $\overline{x^{2}}$ & RMSEA & GFI & $\overline{\text { AGFI }}$ & CFI & $\overline{\mathrm{NFI}}$ & \\
\hline Observed Value & $\begin{array}{l}242 \\
p=.77\end{array}$ & .040 & .99 & .98 & .98 & .98 & .93 \\
\hline Level of acceptance & $p>.05$ & $<.05$ & $>.90$ & $>.90$ & $>.90$ & $>.90$ & $<3$ \\
\hline
\end{tabular}

RMSEA root mean square error of approximation; GFI goodness of fit index; AGFI adjusted goodness of fit index; CFI Comparative fit index; NFI normed fit index; $x^{2}$ Chi-squared test; $d f$ Degrees of Freedom. 
well-grounded conclusions about the reliability and validity of the Mini-MAC instrument for its future application, both analyses were adopted in the current study. The five factor measurement model showed an excellent fit according to the cut-off values of absolute, incremental and parsimonious fit indices. The fitness indices were supported by strong literature being referred [41]. The evidences of the validity and reliability aspects were infered from CFA measurements. However, this validity remains highly limited by place, time, and use of the scores resulting from the measurement operation, which was conducted on studies with small samples. Therefore, a study carried out at one location with one type of population may generate findings that are hardly to generalize to another sample from different location and/or population.

\section{Conclusions}

Overall, this work represents the first validation of the Arabic version of the Mini-MAC instrument. We investigated its psychometric properties among a sample of 203 Moroccan breast cancer women using CFA to examine its factor structure. However, this study has some limitations that should be highlighted. The sampling was conducted in a single regional hospital and targeted a small sample size of cancer patients with a specific type of cancer. In addition, the sample is small and contains patients with different age range, cancer stages of the disease, and subject to different medical care at one Hospital. Hence, these findings cannot, however, be extrapolated to all Moroccan cancer patients from different regions. Thus, further studies on larger samples of different populations that depict diverse types, and stages of cancer are required. Moreover, longitudinal surveys are needed to assess the predictive validity of the scale for psychosocial outcomes. This short version of 24 items is a quick, valid, and reliable instrument in assessing cancer-specific coping of the adjustment response to cancer. It will allow physicians to know how negative and positive psychological adjustment to the illness could affect clinical practice. Hence, the acceptable psychometric properties obtained in this Arabic Mini-MAC guarantee its future use in clinical practice to measure various coping responses of breast cancer women.

\footnotetext{
Abbreviations

AGFI: Adjusted goodness-of-fit index; AP: Anxious preoccupation; ASV: Average shared variance; AVE: Square root of the average variance extracted; $X^{2} / d f$ : Chi square value/degrees of freedom; CA: Cognitive avoidance; CFA: Confirmatory factor analysis; CFl: Comparative fit index; CFI: Bentler comparative fit index; CR: Composite reliability; EFA: Exploratory factor analysis; FA: Fatalism; FS: Fighting spirit; GFI: Goodness of fit index; $\mathrm{HH}$ : Helpless/hopeless; HTMT: Heterotrait-monotrait criterion; Mini-MAC : Mini mental adjustment to cancer; MSV: Maximum shared variance; NFI: Normed fit index; RMSEA: Root mean square error of approximation
}

\section{Acknowledgments}

We are grateful to all the patients who participated in the study. We also thank all the health professionals working in Hassan II University Hospital of Fez who helped us to recruit the participants needed for our study.

\section{Authors' contributions}

MER has been involved in the the conception and design of the study, acquisition of data, analysis and interpretation of data, and drafting the manuscript; JE has carried out the statistical analysis, interpretation of data, and drafting the manuscript; LA has contributed to the conception and design of the study, and acquisition of data; $\mathrm{MO}$ has been involved in the acquisition of data; MA has contributed to the conception, and design of the study; AE has contributed to the conception and design of the study, and acquisition of data; ZB has contributed to the conception and design of the study, and acquisition of data; NM has contributed to the acquisition of data; KE has contributed to the conception and design of the study, $\mathrm{KH}$ has contributed to the conception and design of the study, BZ has contributed to the conception and design of the study, and the acquisition of data, has been involved in revising the manuscript critically, and has given the final approval for the paper to be published. All authors read and approved the manuscript.

\section{Funding}

The Research reported in this publication was supported by Moffitt Cancer Center under the NIH International Fogarty Center for the award number 5D43TW009804, PI Anna Giuliano. The funding bodies played no role in the design of the study and collection, analysis, and interpretation of data and in writing the manuscript.

\section{Availability of data and materials}

The datasets used and analyzed during the current study are available from the corresponding author on reasonable request.

\section{Declarations}

Ethics approval and consent to participate

Ethical approval was obtained from the hospital-university ethics committee of Sidi Mohamed Ben Abdellah University ( $N^{\circ}$ 24/18). All the participants were notified about the aim of the study and had provided written consent before starting the investigation.

\section{Consent for publication}

Not applicable.

\section{Competing interests}

The authors declare that they have no competing interests.

\section{Author details}

'Laboratory of Natural Substances, Pharmacology, Environment, Modeling, Health \& Quality of Life, Faculty of Sciences Dhar El Mahraz, Sidi Mohamed Ben Abdellah University, P. B 1796 Atlas, 30003 Fez, Morocco. ${ }^{2}$ Teachers Training College (Ecole Normale Superieure), Department of Biology and Geology, Sidi Mohamed Ben Abdellah University, P. B 5206 Bensouda, 30030 Fez, Morocco. ${ }^{3}$ Laboratory of Pedagogical and Didactic Engineering of Sciences and Mathematics, Regional Center of Education and Training (CRME F) of Fez. Rue Koweit, P.B 49 Agdal, 30050 Fes, Morocco. ${ }^{4}$ R.N.E Laboratory, Multidisciplinary Faculty of Taza, Sidi Mohamed Ben Abdellah University, P. B 1223, Route Oujda, 35000 Fez, Morocco. ${ }^{5}$ Medical Oncology Department, Hassan II University Hospital, Route Sidi Harazem, 30070 Fez, Morocco. ${ }^{6}$ Laboratory of Epidemiology and Research in Health Sciences, Faculty of Medicine and Pharmacy, Sidi Mohamed Ben Abdellah University, 2.200 Route Sidi Harazem, 30070 Fez, KM, Morocco. ${ }^{7}$ Laboratory of Epidemiology, Clinical Research, and Public Health, Faculty of Medicine and Pharmacy, Mohamed I University, BP724 Hay Al Quods, 60000 Oujda, Morocco. ${ }^{8}$ Mohamed VI University Hospital, Oujda, Morocco. ${ }^{9}$ Teachers Training College (Ecole Normale Superieure), Department of Human and Social Sciences - Education Sciences, Sidi Mohamed Ben Abdellah University, P. B 5206 Bensouda, 30030 Fez, Morocco. 
Received: 19 October 2020 Accepted: 6 September 2021 Published online: 20 September 2021

\section{References}

1. Garcia de Quevedo I, Lobelo F, Cadena L, Soares M, Pratt M. A comprehensive capacity assessment tool for non-communicable diseases in low- to middle-income countries: development and results of pilot testing. Glob Health Promot. mars 2018;25(1):43-53.

2. Chadli S, Taqarort N, El Houate B, Oulkheir S. Epidemiological transition in Morocco (1960-2015). Méd Santé Trop. 2018;28(2):201-5. https://doi.org/10.1 684/mst.2018.0800.

3. Kim SH, Choe YH, Han AR, Yeon GJ, Lee GH, Lee BG, et al. Design of a randomized controlled trial of a partnership-based, needs-tailored selfmanagement support intervention for post-treatment breast cancer survivors. BMC Cancer. 2020;20:367.

4. Zehra S, Doyle F, Barry M, Walsh S, Kell MR. Health-related quality of life following breast reconstruction compared to total mastectomy and breastconserving surgery among breast cancer survivors: a systematic review and meta-analysis. Breast Cancer. 2020;27(4):534-66.

5. Lewis PE, Sheng M, Rhodes MM, Jackson KE, Schover LR. Psychosocial concerns of Young African American breast Cancer survivors. J Psychosoc Oncol. 2012;30(2):168-84. https://doi.org/10.1080/07347332.2011.651259.

6. Bray F, Ferlay J, Soerjomataram I, Siegel RL, Torre LA, Jemal A. Global cancer statistics 2018: GLOBOCAN estimates of incidence and mortality worldwide for 36 cancers in 185 countries. CA Cancer J Clin. 2018;68(6):394-424. https://doi.org/10.3322/caac.21492.

7. Warth M, Zöller J, Köhler F, Aguilar-Raab C, Kessler J, Ditzen B. Psychosocial Interventions for Pain Management in Advanced Cancer Patients: a Systematic Review and Meta-analysis. Curr Oncol Rep. 2020;22(1):3.

8. Frazier LD. The past, present, and future of the biopsychosocial model: a review of the biopsychosocial model of health and disease: new philosophical and scientific developments by Derek Bolton and Grant Gillett. New Ideas Psychol. 2020;57:100755. https://doi.org/10.1016/j.newidea psych.2019.100755.

9. García-García T, Carmona-Bayonas A, Jimenez-Fonseca P, Jara C, Beato C, Castelo B, et al. Biopsychosocial and clinical characteristics in patients with resected breast and colon cancer at the beginning and end of adjuvant treatment. BMC Cancer. 2019;19:1143.

10. Nordin K, Berglund G, Terje I, Glimelius B. The mental adjustment to cancer scale-a psychometric analysis and the concept of coping. Psychooncology. 1999:8(3):250-9. https://doi.org/10.1002/(SICI)1099-1611 (199905/06)8:3<250::AID-PON379>3.0.CO;2-J.

11. Lazarus RS, Folkman S. Stress, appraisal, and coping. New York: Springer Publishing Co Inc; 1984. p. 456.

12. Greer S, Moorey S, Watson M. Patients' adjustment to cancer: the mental adjustment to Cancer (MAC) scale vs clinical ratings. J Psychosom Res. 1989; 33(3):373-7. https://doi.org/10.1016/0022-3999(89)90027-5.

13. Vitaliano PP, Russo J, Carr JE, Maiuro RD, Becker J. The ways of coping checklist: revision and psychometric properties. Multivar Behav Res. 1985; 20(1):3-26. https://doi.org/10.1207/s15327906mbr2001_1.

14. Cosway R, Endler NS, Sadler AJ, Deary IJ. The coping inventory for stressful situations: factorial structure and associations with personality traits and psychological health. J Appl Biobehav Res. 2000;5(2):121-43. https://doi. org/10.1111/j.1751-9861.2000.tb00069.x

15. Endler NS, Parker JDA, Summerfeldt $\sqcup$. Coping with health problems: developing a reliable and valid multidimensional measure. Psychol Assess. 1998;10(3):195-205. https://doi.org/10.1037/1040-3590.10.3.195.

16. Bell HM. The adjustment inventory (adult form). Palo Alto, CA, US: Stanford Univ. Press; 1938. (The adjustment inventory (adult form))

17. Dunn SM, Smartt HH, Beeney LJ, Turtle JR. Measurement of Emotional Adjustment in Diabetic Patients: Validity and Reliability of ATT39. Diab Care. 1 sept 1986;9(5):480-489.

18. Watson M, Greer S, Young J, Inayat Q, Burgess C, Robertson B. Development of a questionnaire measure of adjustment to cancer: the MAC scale. Psychol Med. 1988;18(1):203-9. https://doi.org/10.1017/S0033291700002026.

19. Akechi T, Fukue-Saeki M, Kugaya A, Okamura H, Nishiwaki Y, Yamawaki S, et al. Psychometric properties of the Japanese version of the mental adjustment to cancer (MAC) scale. Psychooncology. 2000;9(5):395-401. https://doi.org/10.1002/1099-1611(200009/10)9:5<395::AID-PON472>3.0. $\mathrm{CO} ; 2-\mathrm{O}$
20. Osborne RH, Elsworth GR, Kissane DW, Burke SA, Hopper JL. The mental adjustment to Cancer (MAC) scale: replication and refinement in 632 breast cancer patients. Psychol Med. 1999;29(6):1335-45. https://doi.org/10.1017/ S0033291799001142.

21. Watson M, Law MG, dos Santos M dos, Greer S, Baruch J, Bliss J. The miniMAC: further development of the mental adjustment to cancer scale. J Psychosoc Oncol. 31 oct 1994;12(3):33-46.

22. Anagnostopoulos F, Kolokotroni P, Spanea E, Chryssochoou M. The Minimental adjustment to Cancer (Mini-MAC) scale: construct validation with a Greek sample of breast cancer patients. Psychooncology. 2006;15(1):79-89. https://doi.org/10.1002/pon.924.

23. Andreu Vaillo Y, Murgui Pérez S, Martínez López P, Romero RR. Mini-mental adjustment to Cancer scale: construct validation in Spanish breast cancer patients. J Psychosom Res. 2018;114:38-44. https://doi.org/10.1016/j. jpsychores.2018.09.004

24. Grassi L, Buda P, Cavana L, Annunziata MA, Torta R, Varetto A. Styles of coping with cancer: the Italian version of the Mini-mental adjustment to Cancer (Mini-MAC) scale. Psychooncology. 2005;14(2):115-24. https://doi. org/10.1002/pon.826.

25. Patoo M, Allahyari AA, Moradi AR, Payandeh M. Iranian version of the minimental adjustment to cancer scale: factor structure and psychometric properties. J Psychosoc Oncol. 2 nov 2015;33(6):675-685.

26. Watson M, Homewood J. Mental adjustment to Cancer scale@: psychometric properties in a large cancer cohort. Psychooncology. 2008; 17(11):1146-51. https://doi.org/10.1002/pon.1345.

27. Ho SMY, Kam Fung W, Chan CLW, Watson M, Tsui YKY. Psychometric properties of the Chinese version of the Mini-mental adjustment to Cancer (MINI-MAC) scale. Psychooncology. 2003;12(6):547-56. https://doi.org/10.1 002/pon.672.

28. Bredal IS. The Norwegian version of the Mini-mental adjustment to Cancer scale: factor structure and psychometric properties. Psychooncology. 2010; 19(2):216-21. https://doi.org/10.1002/pon.1564.

29. Hulbert-Williams NJ, Hulbert-Williams L, Whelen L, Mulcare H. The psychological impact of cancer (PIC) scale: development and comparative psychometric testing against the mini-MAC scale in UK and Australian cancer survivors. J Psychosoc Oncol Res Pract. sept 2019;1(2):e8.

30. Kang Jl, Chung HC, Kim SJ, Choi HJ, Ahn JB, Jeung H-C, et al. Standardization of the Korean version of Mini-mental adjustment to Cancer (K-Mini-MAC) scale: factor structure, reliability and validity. Psychooncology. 2008;17(6):592-7. https://doi.org/10.1002/pon.1277.

31. Pereira FMP, Santos CSV de B. Initial validation of the Mini-mental adjustment to Cancer (Mini-MAC) scale: study of Portuguese end-of-life cancer patients. Eur J Oncol Nurs. 2014;18(5):534-9. https://doi.org/10.1016/j. ejon.2014.04.004.

32. Wang W-T, Tu P-C, Liu T-J, Yeh D-C, Hsu W-Y. Mental adjustment at different phases in breast cancer trajectory: re-examination of factor structure of the Mini-MAC and its correlation with distress. Psychooncology. 2012;22(4):76874. https://doi.org/10.1002/pon.3065.

33. Fong TCT, Ho RTH. Re-examining the factor structure and psychometric properties of the Mini-mental adjustment to Cancer scale in a sample of 364 Chinese cancer patients. Support Care Cancer févr. 2015;23(2):353-8. https://doi.org/10.1007/s00520-014-2367-0.

34. Church AT, Burke PJ. Exploratory and confirmatory tests of the big five and Tellegen's three- and four-dimensional models. J Pers Soc Psychol. 1994; 66(1):93-114. https://doi.org/10.1037/0022-3514.66.1.93.

35. Hulbert-Williams NJ, Hulbert-Williams L, Morrison V, Neal RD, Wilkinson C. The Mini-mental adjustment to Cancer scale: re-analysis of its psychometric properties in a sample of 160 mixed cancer patients. Psychooncology. 2011; 21(7):792-7. https://doi.org/10.1002/pon.1994.

36. Czerw Al, Marek E, Deptała A. Use of the mini-MAC scale in the evaluation of mental adjustment to cancer. Współczesna Onkol. 2015;5(5):414-9. https://doi.org/10.5114/wo.2015.54900.

37. Kneier A, Rosenbaum E, Rosenbaum I. Coping with Cancer Ten Steps toward Emotional Well-Being. In: Everyone's Guide to Cancer Supportive Care: A Comprehensive Handbook for Patients and Their Families. Andrews McMeel Publishing (USA); 2005.

38. Mustafa M, Carson-Stevens A, Gillespie D, Edwards AG. Psychological interventions for women with metastatic breast cancer. Cochrane Breast Cancer Group, éditeur. Cochrane Database Syst Rev. 4 juin 2013 [cité 23 mai 2021]; Disponible sur: http://doi.wiley.com/https://doi.org/10.1002/14651858. CD004253.pub4 
39. Cayrou S, Dickès $P$, Gauvain-Piquard A, Rogé B. THE mental adjustment to cancer (MAC) scale: French replication and assessment of positive and negative adjustment dimensions: THE MAC SCALE ON FRENCH CANCER. Psychooncology. 2003;12(1):8-23. https://doi.org/10.1002/pon.634.

40. Pereira MG, Baia V, Machado JC. Coping and quality of life in patients with skin tumors in the follow-up stage: the mediating role of body image and psychological morbidity. J Psychosoc Oncol. 2 sept 2016;34(5):400-412.

41. Hair JF, Black WC, Babin BYJ, Anderson RE. Multivariate data analysis. 8th ed. Andover, Hampshire: Cengage; 2019. 813 p.

42. Mardia KV. Measures of multivariate skewness and kurtosis with applications. Biometrika. 1970;57(3):519-30. https://doi.org/10.1093/biomet/57.3.519.

43. Lim S, Jahng $\mathrm{S}$. Determining the number of factors using parallel analysis and its recent variants. Psychol Methods. 2019;24(4):452-67. https://doi.org/1 $0.1037 /$ met0000230.

44. Yong $A G$, Pearce $S$. A beginner's guide to factor analysis: focusing on exploratory factor analysis. Tutor Quant Methods Psychol. 1 oct 2013;9(2): 79-94.

45. Fornell C, Larcker DF. Structural equation models with unobservable variables and measurement error: algebra and statistics. J Mark Res. 1981; 18(3):382-8. https://doi.org/10.1177/002224378101800313.

46. Hutcheson GD, Sofroniou N. The Multivariate Social Scientist: Introductory Statistics Using Generalized Linear Models. SAGE Publications (USA); 1999. p. 292.

47. Kline RB. Principles and practice of structural equation modeling. 3rd ed. New York: Guilford Press; 2011. p. 427. Methodology in the social sciences

48. Hu L, Bentler PM. Cutoff criteria for fit indexes in covariance structure analysis: conventional criteria versus new alternatives. Struct Equ Model Multidiscip J. 1999;6(1):1-55. https://doi.org/10.1080/10705519909540118.

49. Haut-Commissariat Au Plan. Femmes Marocaines et Marché du Travail : Caractéristiques et Evolutio. Rabat, Maroc: Haut-Commissariat Au Plan. Royaume du Maroc; 2013 déc [cité 2 juin 2021]. Disponible sur: https:// www.hcp.ma/attachment/480863/

50. Charaka H, Khalis M, Elfakir S, Huybrechts I, Khazraji YC, Lyoussi B, et al. Knowledge, Perceptions, and Satisfaction of Moroccan Women Towards a New Breast Cancer Screening Program in Morocco. J Cancer Educ. 24 déc 2019 [cité 22 mai 2021]; Disponible sur: https://doi.org/https://doi.org/10.1 007/s13187-019-01680-6.

51. Traore BM, El Fakir S, Charaka H, Benaicha N, Najdi A, Zidouh A, et al. Evolution of quality of life in patients with breast cancer during the first year of follow-up in Morocco. BMC Cancer. 2018;18(1):109. https://doi.org/1 0.1186/s12885-018-4008-3.

52. El Fakir S, El Rhazi Karima, Zidouh A, Bennani M, Benider A, Errihani H, et al. Health-related quality of life among breast cancer patients and influencing factors in Morocco. Asian Pac J Cancer Prev. déc $2016 ; 17(12)$. [cité 22 mai 2021] Disponible sur: https://doi.org/https://doi.org/10.22034/APJCP.2016.1 7.12.5063

53. Khalis M, Chajès V, Moskal A, Biessy C, Huybrechts I, Rinaldi S, et al. Healthy lifestyle and breast cancer risk: a case-control study in Morocco. Cancer Epidemiol. 2019;58:160-6. https://doi.org/10.1016/j.canep.2018.12.012.

54. Costa-Requena G, Gil F. The mental adjustment to cancer scale: a psychometric analysis in Spanish cancer patients: psychometric analysis of the MAC scale Spanish version. Psychooncology. 2009;18(9):984-91. https:// doi.org/10.1002/pon.1466.

55. Nordin K, Glimelius B. Reactions to gastrointestinal cancer-variation in mental adjustment and emotional well-being over time in patients with different prognoses. Psychooncology. 1998;7(5):413-23. https://doi.org/10.1 002/(SICI)1099-1611(1998090)7:5<413::AID-PON318>3.0.CO;2-Q.

\section{Publisher's Note}

Springer Nature remains neutral with regard to jurisdictional claims in published maps and institutional affiliations.

Ready to submit your research? Choose BMC and benefit from:

- fast, convenient online submission

- thorough peer review by experienced researchers in your field

- rapid publication on acceptance

- support for research data, including large and complex data types

- gold Open Access which fosters wider collaboration and increased citations

- maximum visibility for your research: over $100 \mathrm{M}$ website views per year

At $\mathrm{BMC}$, research is always in progress.

Learn more biomedcentral.com/submissions 